\title{
IMPELEMENTASI MANAJEMEN SARANA DAN PRASARANA DI SEKOLAH MENENGAH KEJURUAN
}

\author{
Hartoni, Amirudin, Subandi \\ IAIM NU Metro Lampung \\ hartoni201501@gmail.com
}

\begin{abstract}
Abstrak
Sarana dan prasarana pendidikan adalah salah satu dari beberapa sumber daya yang penting dalam kemajuan suatu lembaga. Penelitian ini bertujuan; 1) Untuk mendiskripsikan implementasi manajemen sarana prasarana di SMK, 2) Untuk mendeskripsikan proses manajemen sarana dan prasarana di SMK. Desain penelitian ini adalah penelitian deskriptif kualitatif, penelitian yang data-datanya berupa kata-kata yang berasal dari wawancara, catatan laporan, dokumen yang didalamnya mengutamakan untuk pendiskripsian. Penelitian ini memperoleh kesimpulan bahwa, implementasi manajemen sarana prasarana di SMK dilakukan secara optimal dan proses manajemen sarana prasarana pendidikan di SMK dilaksanakan secara berurutan, dimulai dari perencanaan pengadaan, pengadaan, pemeliharaan, inventarisasi dan penghapusan agar selalu dalam kondisi rapih, tertib dan teratur.
\end{abstract}

Kata kunci : Manajemen, Sarana dan Prasarana, Sekolah Menengah Kejuruan 


\section{PENDAHULUAN}

Pendidikan merupakan investasi penting dan memiliki peranan strategis bagi terwujudnya sumber daya manusia yang berkualitas (Irwandani, Latifah, Asyhari, Muzannur, \& Widayanti, 2017; Ayudia, 2014), dan memiliki peran sentral bagi upaya pengembangan sumber daya manusia (Abidin, 2017). Sistem pendidikan harus mampu menjamin peningkatan mutu, relevansi dan efisiensi manajemen pendidikan (Setiawan, 2016). Penyelenggaraan program pendidikan di sekolah tidak akan terlepas dari konsep manajemen pendidikan (Nur, Sari, Bafadal, Wiyono, \& Malang, 2018) dimana sekolah sebagai sebuah lembaga pendidikan yang menyelenggarakan proses belajar mengajar (Bafadal, 2018).

Akhir-akhir ini permasalahan yang terjadi diantaranya yakni; manajemen yag terlalu sentralistrik, terpecah belah dan kakunya proses pembiayaan serta manajemen yang tidak efektif pada jenjang sekolah, banyak kepala sekolah yang belum mampu memaksimalkan peran guru, pengelolaan sarana dan prasarana, serta pengelolaan siswa dengan baik (Batubara \& Ariani, 2017). Kemudian kenyataannya banyak kepala sekolah yang belum mampu memaksimalkan peran guru, pengelolaan sarana dan prasarana, serta pengelolaan siswa dengan baik (Muhammad \& Rahman, 2017). Oleh karena itu kualitas suatu lembaga pendidikan tidak hanya ditentukan oleh kualitas pembelajaran semata, namun juga dipengaruhi bagaimana lembaga pendidikan tersebut mampu mengelola sumber daya manusianya (Komariah, 2018).

Guru merupakan salah satu komponen yang sangat menentukan untuk terselenggaranya proses pendidikan, yaitu sebagai fasilitator dalam proses pembelajaran (Mulyani, 2012). Solusi dalam mengatasi permasalahan diatas adalah, dengan mengelola sarana dan prasarana pendidikan agar dapat berkembang secara dinamis (Novita, Pendahuluan, \& El-islam, 2017), sesuai dengan Peraturan Pemerintah No 19 Tahun 2005 tentang Standar Nasional Pendidikan yang menyangkut standar sarana dan prasarana pendidikan secara nasional pada Bab VII Pasal 42 (Syahputra, 2015). Fasilitas atau sarana dan prasarana pendidikan adalah salah satu dari beberapa sumber daya yang penting, serta merupakan gambaran kemajuan suatu lembaga dalam mendukung sepenuhnya kegiatan pembelajaran (Fauzan, 2018).

Prasarana berarti alat tidak langsung untuk mencapai tujuan. Dalam pendidikan diantaranya; lokasi atau tempat dan bangunan sekolah, sedangkan sarana seperti alat langsung untuk mencapai tujuan pendidikan, diantaranya; ruang, buku, perpmustakaan, laboratorium (Darmawan, 2016). Sarana dan Prasarana adalah komponen penunjang dalam kegiatan belajar mengajar di Sekolah Menengah Kejuruan (SMK), karena SMK sebagai salah satu instansi pendidikan formal yang diharapkan mampu memberikan 
kontribusi secara intensif (Ariyanto, Wiharna, \& Noor, 2017). Oleh karena itu sarana dan prasarana yang mendukung sangat dibutuhkan untuk kelancaran tarnsfer pemahaman konsep dari guru ke siswa (Pratiwi \& Suyatmin, 2017). Berdasarkan uraian diatas peneliti tertarik untuk mengkaji lebih lanjut gambaran yang sebenarnya tentang Implementasi Manajemen Sarana dan Prasarana di SMK.

\section{METODE PENELITIAN}

\section{Desain Penelitian}

Penelitian ini menggunakan metode deskriptif dengan pendekatan kualitatif (Bimantara, Handayani, \& Dwiatmanto, 2017). Penelitian dilakukan di SMK Taruna Bandar Lampung, Informan penelitian didasarkan pada pertimbangan bahwa informan penelitian dapat memberikan informasi yang selengkaplengkapnya dan relevan dengan tujuan penelitian (Rukayat, 2017).

\section{Teknik Pengumpulan Data}

Data kualitatif diperoleh melalui teknik pengumpulan data yakni wawancara, analisis dokumen, diskusi terfokus, atau observasi yang telah dituangkan dalam catatan lapangan (Dady, Ilat, \& Pontoh, 2017).

\section{ANALISIS DATA DAN PEMBAHASAN}

\section{Analisis Data}

Peneliti menyajikan hasil analisis mengenai tanah, halaman, dan gedung sekolah dapat dilihat pada tabel berikut,

Tabel 1. Keadaan Tanah SMK Taruna Bandar Lampung

\begin{tabular}{ccccc}
\hline \multicolumn{5}{c}{ Kepemilikan } \\
\hline $\begin{array}{c}\text { Sunber } \\
\text { Tanah }\end{array}$ & $\begin{array}{c}\text { Sudah } \\
\text { Sertifik } \\
\text { at }\end{array}$ & $\begin{array}{c}\text { Belum } \\
\text { sertifik } \\
\text { at }\end{array}$ & $\begin{array}{c}\text { Sudah } \\
\text { diguna } \\
\text { kan } \\
\left(\mathrm{m}^{2}\right)\end{array}$ & $\begin{array}{c}\text { Belu } \\
\mathrm{m} \\
\text { digun } \\
\text { akan } \\
\left(\mathrm{m}^{2}\right)\end{array}$ \\
\hline Yayasan & $\begin{array}{c}2000 \\
\mathrm{~m}^{2}\end{array}$ & - & $\begin{array}{c}2000 \\
\mathrm{~m}^{2}\end{array}$ & - \\
\hline Pemerintah & - & - & - & - \\
\hline $\begin{array}{c}\text { Wakap/Su } \\
\text { mbangan }\end{array}$ & - & - & - & - \\
\hline $\begin{array}{c}\text { Pinjam/Se } \\
\text { wa/Beli }\end{array}$ & - & - & - & - \\
\hline
\end{tabular}

Berdasarkan tabel 1, terlihat bahwa tanah SMK Taruna Bandar Lampung sepenuhnya milik negara.Luas areal seluruhnya $2.000 \mathrm{~m}^{2}$. Seluruh tanah tersebut sudah digunakan untuk kegiatan belajar mengajar. Setelah diperoleh 
data, bahwa bangunan Sekolah pada umumnya dalam kondisi baik. Jumlah ruang kelas untuk menunjang kegiatan belajar mengajar sangat memadai. Peneliti menyajikan hasil analisis keadaan sarana dan prasarana sekolah dapat dilihat pada tabel berikut.

Tabel. 2 Keadaan Sarana Dan Prasarana SMK Taruna Bandar Lampung

\begin{tabular}{cccc}
\hline No & $\begin{array}{c}\text { Nama Sarana dan } \\
\text { Prasarana }\end{array}$ & Jumlah & Keadaan \\
\hline 1 & Gedung & 9 & Baik \\
\hline 2 & $\begin{array}{c}\text { Ruang Kepala } \\
\text { Sekolah }\end{array}$ & 1 & Baik \\
\hline 3 & Ruang Guru & 1 & Baik \\
\hline 4 & Ruang UKS & 1 & Baik \\
\hline 5 & Ruang BK/BP & 1 & Baik \\
\hline 6 & Ruang Osis & 1 & Baik \\
\hline 7 & Mushollah & 1 & Baik \\
\hline 8 & Ruang TU & 1 & Baik \\
\hline 9 & Ruang Lab. Bahasa & 1 & Baik \\
\hline 10 & $\begin{array}{c}\text { Ruang Lab. } \\
\text { Komputer }\end{array}$ & 1 & Baik \\
\hline 11 & Ruang Perpustakaan & 1 & Baik \\
\hline 12 & $\begin{array}{c}\text { Lapangan Olah } \\
\text { Raga }\end{array}$ & 1 & Baik \\
\hline 13 & Kantin & 1 & Baik \\
\hline 14 & Gudang & 1 & Baik \\
\hline 15 & Kamar mandi/WC & 8 & Baik \\
\hline 16 & Komputer & 15 & Baik \\
\hline 17 & Printer & 2 & Baik \\
\hline
\end{tabular}

Berdasarkan tabel 2, terlihat bahwa di SMK Taruna Bandar Lampung sarana prasarana yang adas angat memadai dalam menunjang proses pendidikan. Sehingga kapanpun dibutuhkan oleh personel sekolah selalu siap pakai. Jumlah sarana prasarana yang dimiliki SMK Taruna Bandar Lampung sangat relevan dengan kebutuhan siswa dan tidak ketinggalan zaman.

\section{Pembahasan}

Dalam kaitannya dengan implementasi sarana dan prasarana, ketersesdiaan sarana dan prasrana merupakan salah satu komponen penting harus dipenuhi dalam menunjang sistem pendidikan. Manajemen sarana dan prasarana pendidikan dapat diartikan sebagai segenap proses pengadaan dan pendayagunaan komponen secara lansung maupun tidak lansung menunjang proses pendidikan untuk mencapai tujuan pendidikan secara efektif dan efisien. 
Berdasarkan penelitian yang peneliti lakukan semenjak tanggal 28 januari2016 sampai dengan tanggal 10 Februari 2016 dengan menggunakan tekhnik interview/ wawancara baik secara langsung maupun tidak langsung,maka dapat peneliti paparkan beberapa data dari para informan yang terkait dengan judul "Implementasi Manajemen Sarana Prasarana dan Prasarana di SMK Taruna Bandar Lampung.

Sarana dan prasarana pendidikan di SMK Taruna Bandar Lampung selalu diperbaharui dan ditingkatkan sesuai dengan perkembangan ilmu pengetahuan yang semakin maju dan pesat, dengan tujuan tidak lain adalah dalam rangka meningkatkan kualitas pendidikan. Berdasarkan wawancara dengan bapak Selamet Rajito, selaku Waka sarpras SMK Taruna Bandar Lampung dan manajemen sarana dan prasarana pendidikan biasanya ditangani oleh beberapa pegawai yang benar-benar ahli dalam bidangnya, akan tetapi hal tersebut tidak terlepas dari peran guru, seperti halnya di SMK Taruna Bandar Lampung.

Sarana dan prasarana pendidikan merupakan komponen yang sangat penting dalam setiap aktifitas pendidikan terutama untuk menunjang kesuksesan dalam kegiatan belajar mengajar, maka dalam pelaksanaanya SMK Taruna Bandar Lampung mengupayakan seoptimal mungkin dalam mengelola sarana prasarana dengan ditangani para pegawai dan dibantu oleh para guru. Dengan kemajuan pendidikan, SMK Taruna Bandar Lampung selalu melakukan pembaharuan di semua bidang salah satunya dalam bidang sarana prasaran.

Keberadaan sarana dan prasarana pendidikan di sekolah tidak langsungada begitu saja. Sarana dan prasarana ada tentunya juga melalui beberapa proses yang panjang dan rumit. Di SMK Taruna Bandar Lampung dalam meningkatkan dan mengembangkan sarana dan prasarana juga melalui beberapa proses yang tidak mudah, diantaranya meliputi: Perencanaan Penggadaan, Pengadaan, Pendistributian, Pemeliharaan dan Perawatan, Inventarisasi dan Penghapusan. Perencanaan pengadaan harus dirancang dengan benar sebelum penggadaan dilakukan.Bila rencana dari awal sudah matang maka sangatberpengaruh terhadap hasil yang diperoleh setelah penggadaan. Perencanaan di SMK Taruna Bandar Lampung dilakukan dengan meneliti kembali perlengkapan yang ada di sekolah. Dengan demikian baru dapat menentukan perlengkapan yang dibutuhkan.

Penggadaan terhadap sarana dan prasarana yang dibutuhkan dalam menunjang terlaksananya kegiatan belajar mengajar sudah selazimnya harus dilaksanakan dengan baik dan benar. Kelancaran kegiatan dalam proses belajar mengajar akan membawahasil yang maksimal, ketika dalam proses penggadaan benar-benarmemperhatikan terhadap kebutuhan paling pokok dalam menunjangkeberhasilan kegiatan belajar mengajar. Untuk dana 
pengadaan sarana prasarana pendidikan, Sesuai hasil wawancara dengan Bapak Hikmatullah.

Pemeliharaan sarana dan prasarana di SMK Taruna Bandar Lampung merupakan tanggung jawab seluruh civitas akademik.Hal tersebut dilakukan supaya sarana dan prasarana yang ada selalu dalam kondisi baikdan tidak mudah rusak. Akan tetapi itu semua juga perlu kesadaran dariseluruh personel yang ada di sekolah ini supaya mempunyai rasa tanggung jawab yang besar terhadap sarana dan prasarana yang di miliki oleh Sekolah. Penuturan dari wakil kepala sekolah bagian sarana dan prasarana itu sama dengan hasil wawancara yang penulis lakukan dengan kepala sekolah, bahwa dalam tahapan pemberian kode barang untuk sarana dan prasarana yang ada sedang dilakukan proses, karena dalam pemberian kode barang harus melewati prosedur yang panjang dan membutuhkan banyak waktu dalam kegiatan tersebut.

\section{SIMPULAN DAN SARAN Simpulan}

Penelitian ini memperoleh kesimpulan bahwa, implementasi manajemen sarana prasarana di SMK Taruna Bandar Lampung, selalu dilakukan secara optimal. Hal tersebut nampak pada kelengkapan sarana prasarana yang dimiliki oleh SMK Taruna Bandar Lampung menangani sarana prasarana tersebut langsung ditangani oleh guru bidang studi masingmasing dibawah pengawasan Waka sarana prasarana hal tersebut bertujuan agar lebih efektif dan efesien, kemudian proses manajemen sarana prasarana pendidikan, SMK Taruna Bandar Lampung melaksanakan secara berurutan, dimulai dari perencanaan pengadaan, pengadaan,, pemeliharaan, inventarisasi dan penghapusan. Proses tersebut di lakukan supaya sarana prasrana di madrasah tersebut selalu dalam kondisi rapih, tertib dan teratur.

\section{Saran}

Implementasi manajemen sarana prasarana hendaknya ditangani oleh orang yang benar-benar ahli dalam mengelola sarana prasarana tersebut sehingga kapanpun sarana prasarana tersebut dibutuhkan selalu dalam kondisi siap pakai. Sehingga keterlibatan tidak sepenuhnya ikut andil, dengan begitu tugas guru sebagai pendidik tidak terpecah belah, serta proses manajemen sarana prasarana seyogyanya direncanakan lebih matang lagi terhadap kebutuhan dalam proses belajar mengajar sesuai dengan dana yang ada. 


\section{REFERENSI}

Abidin, A. A. (2017). Manajemen Pembiayaan Pendidikan Tinggi Dalam Upaya Peningkatan Mutu. Jurnal Penjaminan Mutu, 87-99.

Ariyanto, D., Wiharna, O., \& Noor, R. A. M. (2017). Studi Eksplorasi

Sarana Dan Prasarana Praktik Pada Mata Pelajaran Pemeliharaan Chasis

Dan Pemindah Tenaga Di Smk. Journal of Mechanical Engineering Education, 4(2), 163-168.

Bafadal, I. (2018). Manajemen Implementasi Kurikulum Dan Pembelajaran Berbasis Tauhid Dalam Pembentukan Karakter Peserta Didik. Jurnal Adminitrasi Dan Manajemen Pendidikan, 1(2), 188-197.

Batubara, H. H., \& Ariani, D. N. (2017). Implementasi Manajemen Berbasis

Sekolah Di Sdn Sungai Miai 5 Dan Sdn Surgi Mufti 4 Di Banjarmasin. JURNAL ILMU SOSIAL DAN HUMANIORA, 3(2), 452-461.

Bimantara, Z. A., Handayani, S. R., \& Dwiatmanto. (2017). Analisis Pengendalian Intern Dalam Sistem Akuntansi Pasien Umum ( Studi Pada Rumah Sakit Ibnu Sina Bojonegoro ). Jurnal Administrasi Bisnis $(J A B), \quad 45(1), \quad$ 203-209. Retrieved from http://administrasibisnis.studentjournal.ub.ac.id/index.php/jab/article/vi ew/1775/2147

Dady, F., Ilat, V., \& Pontoh, W. (2017). Analisis Sistem Akuntansi Dan Prosedur Pembayaran Klaim Jaminan Kematian Pada Pt. Taspen (Persero) Cabang Manado. Jurnal Riset Akuntansi Going Concern, 12(1), 63-72.

Darmawan, B. (2016). Pengaruh layanan pembelajaran, sarana-prasarana, kerjasama institusi, dan pemasaran lulusan terhadap kepuasaan siswa. Jurnal Administrasi Pendidikan, XX111(1), 141-167.

Fauzan, A. (2018). Manajemen Sarana Dan Prasarana Hisbullah Natar Lampung Selatan. Jurnal Kajian Ilmu Pendidikan, 3(1), 249-276.

Irwandani, I., Latifah, S., Asyhari, A., Muzannur, M., \& Widayanti, W. (2017). Modul Digital Iinteraktif Berbasis Articulate Studio'13: Pengembangan pada Materi Gerak Melingkar Kelas x. Jurnal Ilmiah Pendidikan Fisika Al-Biruni, 06(2), 221-231. https://doi.org/10.24042/jipfalbiruni.v6i2.1862

Komariah, N. (2018). Implementasi Fungsi Manajemen Pendidikan di SDI Wirausaha Indonesia. Jurnal Perspektif, 16(1), 107-112.

Muhammad, S., \& Rahman, M. (2017). Implementasi Manajemen Berbasis Sekolah Untuk Meningkatkan Mutu Sekolah Dasar Islam Insan Kamil Bacan Kabupaten Halmahera Selatan. Jurnal Pendidikan, 15(25), 610 620.

Mulyani, A. (2012). Pengaruh Kinerja Kepala Sekolah Dan Kinerja Guru Terhadap Mutu Pembelajaran Pada Smk Sekabupaten Purwakarta. 
Jurnal Adminisistrasi Pendidikan, 14(1), 86-92.

Novita, M., Pendahuluan, A., \& El-islam, N. (2017). Sarana dan prasarana yang baik menjadi bagian ujung tombak keberhasilan lembaga pendidikan islam. Jurnal Nur El-Islam, 4(2), 97-129.

Nur, D., Sari, A., Bafadal, I., Wiyono, B. B., \& Malang, U. N. (2018). Implementasi Manajemen Berbasis Sekolah. Jurnal Administrasi Dan Manajemen Pendidikan, 1(2), 213-221.

Pratiwi, K., \& Suyatmin. (2017). Dukungan Kualitas Input Siswa , Komitmen Guru, Sarana Dan Prasarana Terhadap Kemandirian Belajar Kimia Di Smk. Jurnal Managemen Pendidikan, 13(1), 91-107.

Rukayat, Y. (2017). Kualitas Pelayanan Publik Bidang Administrasi Kependudukan Di Kecamatan Pasirjambu. Jurnal Ilmiah Magister Ilmu Administrasi (JIMIA), (2), 56-65. Retrieved from http://eprints.uny.ac.id/17523/1/SKRIPSI FULL.pdf

Setiawan, D. F. (2016). Relevansi Rencana Pembelajaran Dalaminternational Standar Organisation (Iso) 9001:2008 Terhadap Rencana Pembelajaran Dalam Standar Proses Sekolah Menengah Kejuruan (Smk) David. Jurnal Equilibria Pendidikan, 1(1), 13-26.

Syahputra, E. (2015). Pengaruh Motivasi Belajar, Sarana Prasarana Belajar, Dan Kemampuan Mengajar Guru Terhadap Siswa Di Smpn 1 Kecamatan. Pagu Kabupaten. Kediri. Jurnal Aplikasi Administrasi, 18(1), 50-65. 